\title{
INVESTIGATIONS ON ELECTRONIC MATERIALS
}

\author{
T. KORMÁNY \\ Research Institute for Telecommunications, Budapest, Hungary \\ and \\ E. PUGNOR \\ Technical University, Chair of Analytical Chemistry, Budapest
}

(Received April 16, 1981; in final form October 20, 1981)

\begin{abstract}
Electronics has been described as a materials oriented technology. In this sense a short review is given concerning
- the connection of materials characterization to the design and processing of electronic components;

- the most important materials characterization methods used for electronic materials;

- the strategy of organizing a complete material characterization system for selected electronic components.
\end{abstract}

\section{INTRODUCTION}

Electronics has been described as a materials oriented technology because in no other area of engineering is there so intimate a relationship between engineering design and materials science and technology as in the electronic device field.

The device engineer should not only be able to design discrete solid state devices but he should comprehend the role that materials science and technology plays in making a given device reliable and workable.

These facts stressed the need for the device engineer to be not only familiar with the role of materials in a given electronic component but to

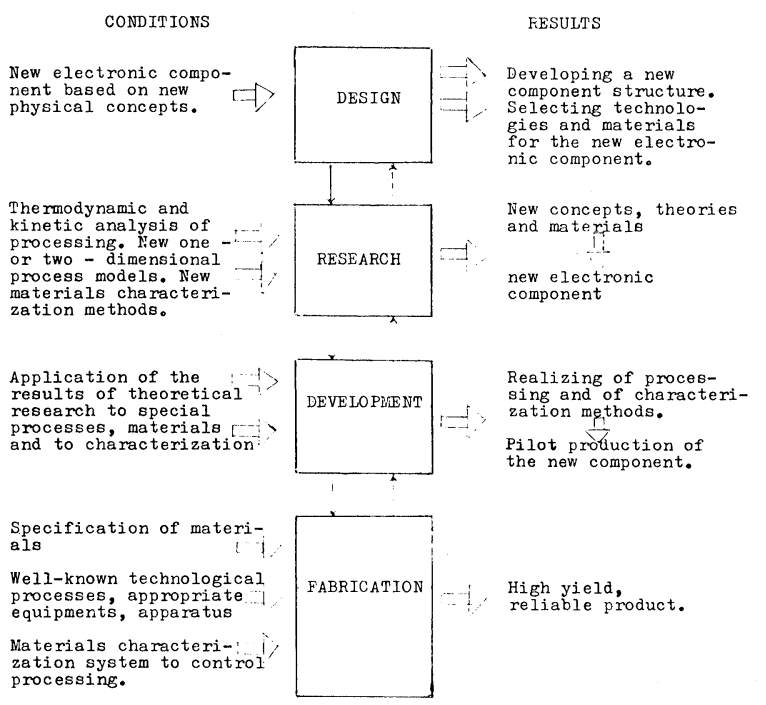

FIGURE 1 Generalized flow chart of electronic components fabrication. apply the results of materials science based on materials characterization.

On the other hand materials characterization helps the process engineer to recognize the basic properties of materials as well as the interaction between processed materials on both the microscopic and submicroscopic levels and to control by a materials characterization system the whole fabrication process of electronic components.

In this paper a short review is given concerning

- the connection of materials characterization to the design and processing of electronic components;

- the most important materials characterization methods used for electronic materials;

- the strategy of organizing a complete material characterization system for selected electronic components.

\section{MATERIALS CHARACTERIZATION VIA DESIGN AND PROCESSING OF ELECTRONIC COMPONENTS}

The first figure shows the scheme of the stages leading to new or improved electronic components. There exists a feedback along the chain. Materials specifications imposed by combined device and circuit requirements must be secured by providing an adequate materials supply and controlled by an appropriate characterization system. The second figure represents those important activities in which materials characterization is intimately involved. The research, development and fabrication of any electronic component, especially of the sophisticated microelectronic ones, implies the request for knowledge of the relationship between the composition-and structure of material 


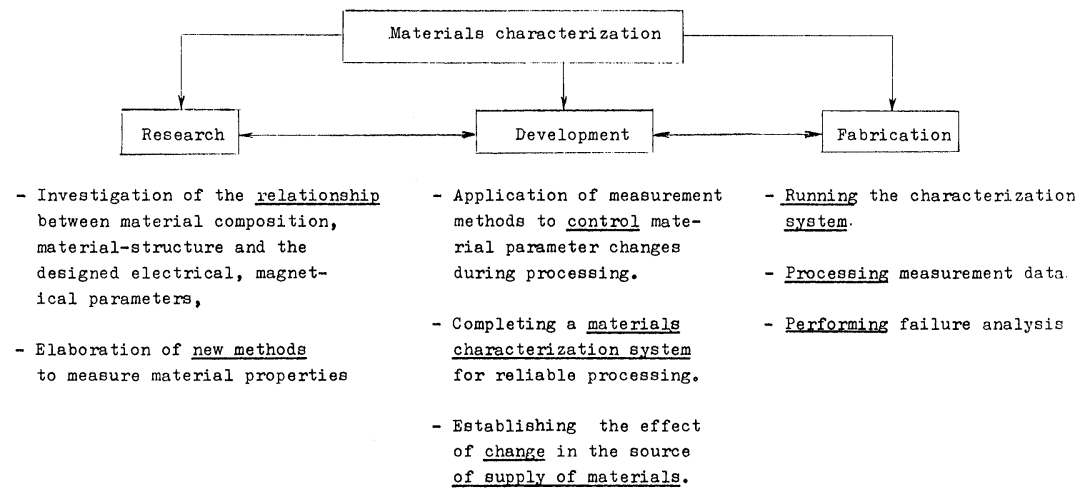

FIGURE 2 Important activities in materials characterization.

and its electrical or magnetic parameters, for the elaboration of methods to measure material properties, for the application of these methods to control material parameter changes during processing with the aim to establish and run a complete material characterization system during fabrication.

\section{MATERIALS USED FOR ELECTRONIC COMPONENTS AND THEIR CHARACTERIZATION}

A great variety of different, very pure "electronic grade" materials are used for the fabrication of electronic components (see Figure 3).

In electronic materials characterization interest has shifted in recent years from the investigation of bulk properties to those of surfaces and films, from average compositions to three dimensional concentration profiles, from overall properties to the characterization of microvolumes. (see Figure 4).

In this context, we define surface as the outermost atomic layer bounding the solid, while the thickness of a film is presumed to lie in the range $10 \mathrm{~nm}-100 \mu \mathrm{m}$, the volume of a microvolume means some $\mu \mathrm{m}$ 3's.

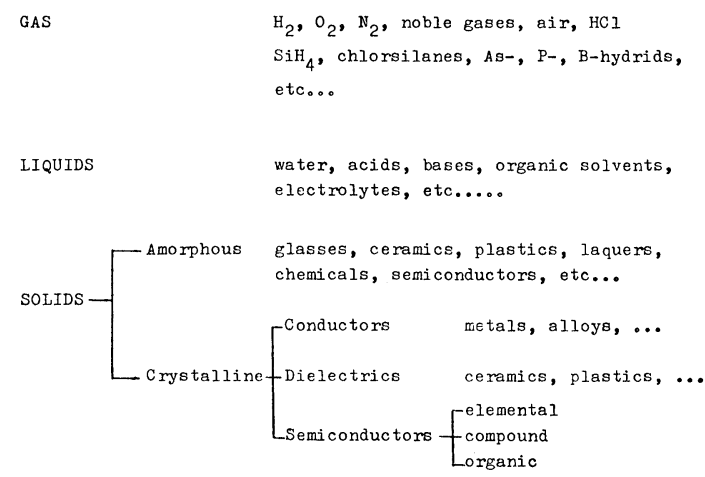

FIGURE 3 Materials used for electronic components.
As there exist such a bewildering array of modern instrumentation, most of which developed only in recent years, it is desirable first to list these methods, (Figure 5) then to consider the factors which determine their choice and to present briefly their use in a given materials characterization system.

The listing is done in columns indicating the different signals detected. The methods generally used for surfaces and films are underlined. Some special methods e.g. determination of surface composition by analysis of neutron and ion-impact radiation, ioninduced X-rays, etc. that are of considerable interest in surface and thin film analysis but for which instrumentation is not yet commercially available will not be included.

There are a number of major considerations which determine the choice of an instrumental method to solve a specific problem in bulk, - surface- or filmanalysis. These considerations include:

-area and depth to be sampled,

- sensitivity and reproducibility,

- number of detectable elements,

- equipment price.

In addition, there are many pertinent interrelated specific parameters which need to be considered in some detail.

They include:

- the effect of the matrix on impurity sensitivity;

- geometric effects;

- charge-up problems with insulating samples;

- the field-induced motion of ionized impurities;

- beam induced chemical changes in the sample;

- the crater size and shape versus detected area when using sputtering techniques; 


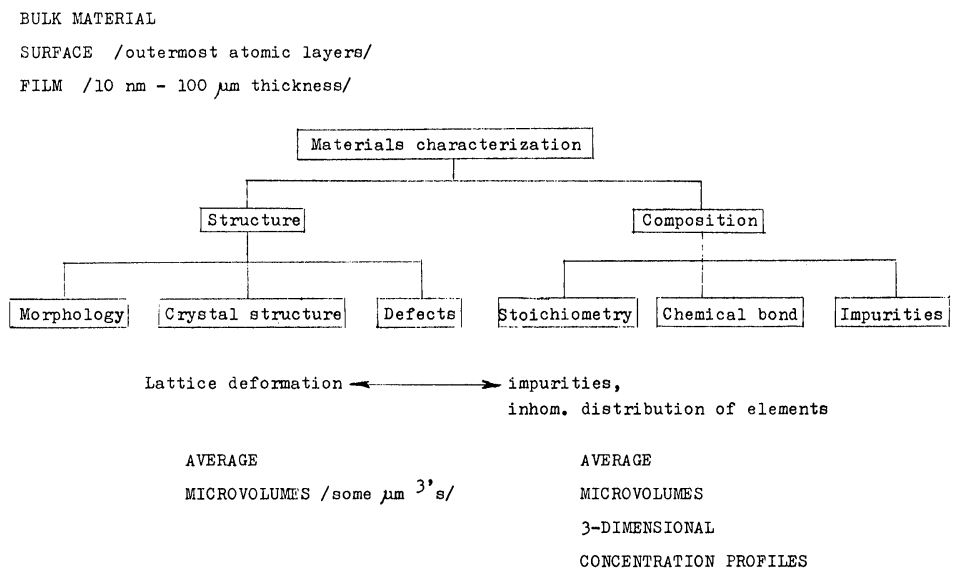

FIGURE 4 Materials characterization of surfaces and films.

- primary beam size, rastering and line- and areascans, lateral concentration profiles and resolution;

- mass resolution;

-sputtering rates and preferential sputtering/depth scale/;

- surface particle versus sputtered species detection;

-lattice damage within the primary ion penetration depth;

- the sample consumed analysis;

- the time spent on the complete analysis and data processing;

\section{MATERIALS CHARACTERIZATION SYSTEM FOR FABRICATION OF HIGH-FREQUENCY SI-EPITAXIAL PLANAR DIODES}

In the manufacturing process of high frequency Si-epitaxial planar diodes a thin n-type single crystalline Si-layer is deposited onto the Si- single crystal wafers using CVD-technology.

The device is fabricated in the epitaxial layer by conventional thermal oxidation, $\mathrm{p}^{+}$-type diffusion or ion-implantation and metallization techniques. The $\mathrm{n}^{+}$ -type dislocation free $\mathrm{Si}$ single crystal substrate wafer essentially provides a mechanical support for the epitaxial film with some advantages in terms of device design.

The properties of the substrate crystal were considered to be rather important because they can degrade the quality of the epitaxial film.

The materials characterization system is based on

- quality control of polished substrate wafers, - quality control of Si-epitaxial layers, -investigation of material- and process-induced "electrically active" defects,

- analysis of the operating device by voltage contrast display.

This system is an overall experimental methodology which includes:

device design, material technology, wafer processing, analytical techniques.

\subsection{Quality Control of Polished Substrate Wafers}

Polished wafers are subjected to a series of inspections divided into the following categories:

- visual

- mechanical

- electrical e.g. resistivity gradient measured by the spreading resistance technique, "SRT"

-structural e.g. defects and inhomogeneities measured by EBIC-microscopy and

- chemical e.g. 0 - content measured by IRS

Visual inspections are normally conducted with the unaided eye but include requirements for both fluorescent and high intensity lighting. Both front and back surfaces are inspected for cracks, pits, scratches, stains and other imperfections including edge curvature.

Mechanical inspections include measurement of wafer bow, flatness, surface roughness and measurements of diameter, flat orientation and thickness.

Electrical investigations include determination of conductivity type, measurement of resistivity gradient, bulk resistivity and their variation. 
The examination of crystal imperfections includes:

- measurement of the oxidation-induced stacking fault count after the required thermal oxidation and etching,

- detection of crystal defects by chemical etching, $\mathrm{X}$-Ray topography and EBIC-microscopy.

Chemical investigations usually mean the measurement of oxygen content and distribution by IR-Spectroscopy.

\subsection{Quality Control of Si-epitaxial Layers}

It has been established earlier ${ }^{2}$ that the tight control of layer thickness and dopant distribution in the Si-epitaxial layer determines - first of all - the yield and reproducibility of high frequency diodes. To influence these parameters an optimization strategy has been developed for the technological process ${ }^{3-5}$ and a series of measurement methods applied in quality control:

- determination of layer thickness by IRS,

- measurement of dopant distribution in the Si-epitaxial layer vertically by SIMS and NAA,

- determination of charge carrier distribution by electrical measurements CV-curves, SRT

\subsection{Material- and Process-induced Defects}

Special emphasis was placed on the inhomogeneities ${ }^{6,7}$ in dislocation free Si-crystals which can be detected by a variety on analytical techniques ${ }^{8,9}$, e.g. X-ray topography, EBIC-microscopy, high voltage transmission electron microscopy. The most common manifestations of these defects are: non-uniform axial segregation during freezing, radial dopant microinhomogeneities due to microsegregation and rotation, and the formation of impurity-point defect complexes. The micro-inhomogeneities and impurity complexes are attributed to crystal interface growth instabilities such as: fluctuation of the growth velocity, thermal asymmetry of the melt, non-steady state melt convection and mechanical and electrical instabilities in the crystal puller.

But these defects, micro-inhomogeneities, impurity complexes, dislocation loops, are often transformed during subsequent wafer processing to produce the final defect structure, complex dislocation colonies and precipitates, which bears little resemblance to the initial defect. The progressive development of native defects during thermal oxidation and diffusion have been investigated by EBIC-microscopy.

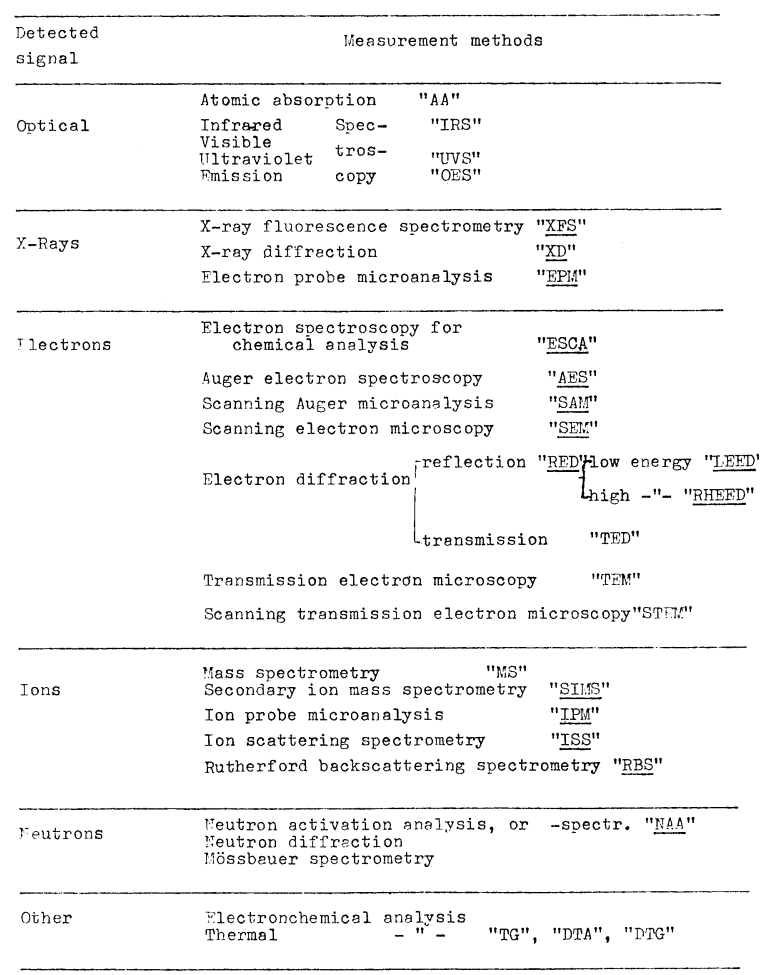

FIGURE 5 Survey of major methods of materials characterization.

The results clearly indicate that a complex relationship exists between major processing steps and the final defect structure, the latter causing the progressive degradation of the electrical characteristics of the pn-junction device. ${ }^{10-13}$

The growth and development of defects during processing could in principle be monitored nondestructively on an appropriately designed test device. In a typical manufacturing operation, this procedure is hardly feasible because of the time lag required for the analysis; however it has to be applied in the phase of research and development and to pilot-plant production.

The information obtained for test devices using EBIC-microscopy has been combined with conventional DC parametric and functional testing of the device produced to establish a statistical relationship between product yield and defect mechanism.

Other important device quality-defining factors are the oxygen and carbon contents of the substrate Si-crystal. The fundamental properties of dissolved oxygen in silicon crystals have been reviewed some years ago by Patel. ${ }^{14}$

The concentration of these impurities in $\mathrm{CZ}$ crystal and their axial and radial distributions in the 
ingot were measured in the characterization system, too.

\subsection{Analysis of the Operating Device by Voltage Contrast Display}

The mentioned testing of diodes by EBIC microscopy will produce sufficient information for a thorough diagnosis of the diode structure.

However, when additional information is required for functional analysis of the high frequency diode, which cannot be obtained with conventional electrical test methods, the non-destructive voltage contrast microscopy, a special mode of SEM, is currently used. There are basically two methods of detecting periodically varying surface voltages using a time resolved detection technique: stroboscopic scanning and time sampling.

In this paper we have tried to review some efforts made in Hungary to establish a material characteristic tion system applied in the manufacturing of high frequency Si-diodes.

Similar work is or will be done for complex integrated circuits monolithic and hybrid, electromechanical components, etc., too.

\section{ANALYTICAL CHEMISTRY}

Last but not least, let us present some remarks concerning the future of analytical chemistry ${ }^{15}$ in electronics.

We think the most concise way to define Analytical Chemistry is to call it the discipline of methodology in creating an image of the substance. It is a way of thinking to clarify the information derived from the signals of the interaction between material and energy or material by selecting the appropriate signals from the signals measured, translating them into forms corresponding to the qualitative and quantitative data of the substance.

The application of methods and examining techniques elaborated so far would by itself not call for analytical chemical research. The factor of decisive importance in predicting the future of Analytical Chemistry is the phenomenon that the increase in quantitative demands is almost always linked with increased qualitative requirements; moreover, the customer needs complex data to be able to get an insight into the most subtle characteristics of the substance. This statement is especially valid for the electronic industry where the behaviour of the substance depends considerably on the distribution of a minute quantity of the components in time and space, new microfabrication technologies, VLSIcircuits. Therefore we predict that the thirst for more information through Analytical Chemistry will be increasing further.

\section{CONCLUSION}

The manufacture of electronic components, especially of the sophisticated microelectronic ones, requires a complete material characterization system during fabrication. To run such a system some R \& D tasks have to be solved especially

- the relationship between the composition- and structure of materials and its electrical or magnetic parameters have to be established,

- methods to measure the most important material properties must be elaborated.

The characteristic feature of such a system lies in the joint application of device design, material technology, processing and analytical techniques.

\section{REFERENCES}

1. G. Kósza, H. Rausch, T. Kormany, The influence of the substrate on interface properties of homoepitaxial silicon layers Thin Solid Films, 12, 99-103 (1972).

2. G. Kósza, H. Rausch, T. Kormány, L. Nagy, Decreasing the autodoping in silicon epitaxial layers grown by the $\mathrm{SiCl}_{4}$-process Proc. 3. Int. Conf. on Vapour Growth and Epitaxy, Amsterdam, p.31 (1975).

3. G. Kósza, T. Kormány, L. Nagy, Epitaxial growth of silicon single crystal layers, HCCG-2-Mattrafüred (1979).

4. G. Kósza, T.A. Kuznetsov, T. Kormány, L. Nagy, Epitaxial process optimization in a horizontal reactor Proc. of the ECCG-2, Lancaster, p. 26 (1979).

5. G. Kósza, T.A. Kuznetsov, T. Kormány, L. Nagy, J. Cryst. Growth, will be published.

6. T. Kormány, L. Vecsernyés, M. Vértesy, E. Jutasi, Untersuchung der durch Metallspuren verursachten Störstellen in Si-Epitaxieschichten Kristall u. Technik 6, 2. 298-306 (1971).

7. L. Fetter, P. Gaworzewski, G. Kósza, T. Kormány, M. Kittler, H. Richter, G. Weidner, Microdefect formation and behaviour in high temperature processes, Proc. 6th Microcoll. Vol 2. - V 1/5.1-5.6 (1978).

8. H.R. Huff and R.R. Burgess Eds, Semiconductor Silicon 1973, Part II. Material Prep. and Characterization. Electrochem. Soc. Inc. Princeton, N.I.

9. P.A. Barness, G.A. Rozgonyi Eds. Semiconductor Characterization Techniques. Electrochem. Soc. Inc. Princeton, N.J. (1978).

10. T. Kormány, G. Nagy, Electron-probe: tool for failure analyses of semiconductor devices, Vacuum, 22, 11. 501-502 (1972). 
11. T. Kormåny, G. Nagy, Die Lősung von Halbleiterproblemen mit der Elektronenstrahlmikrosonde, Kristall $u$. Technik 8, 11. 1201-1208. (1973).

12. T. Kormány, G. Nagy, Failure-analysis of microwave diodes Proc. V. Microcoll SM 211-220, (1974).

13. I. Kiss, T. Kormány, L. Nagy, Reliability aspects of epitaxial-planar-varactor structures Technical Digest, IED-Meeting Washington (1975).

14. J.R. Patel, Semiconductor Silicon 1977, p. 521, Electrochem. Soc. 140. Princeton, N.J.

15. E. Pungor, The future of analytical chemistry Fresenius Z. Anal. Chem. 300, 12-13 (1980). 

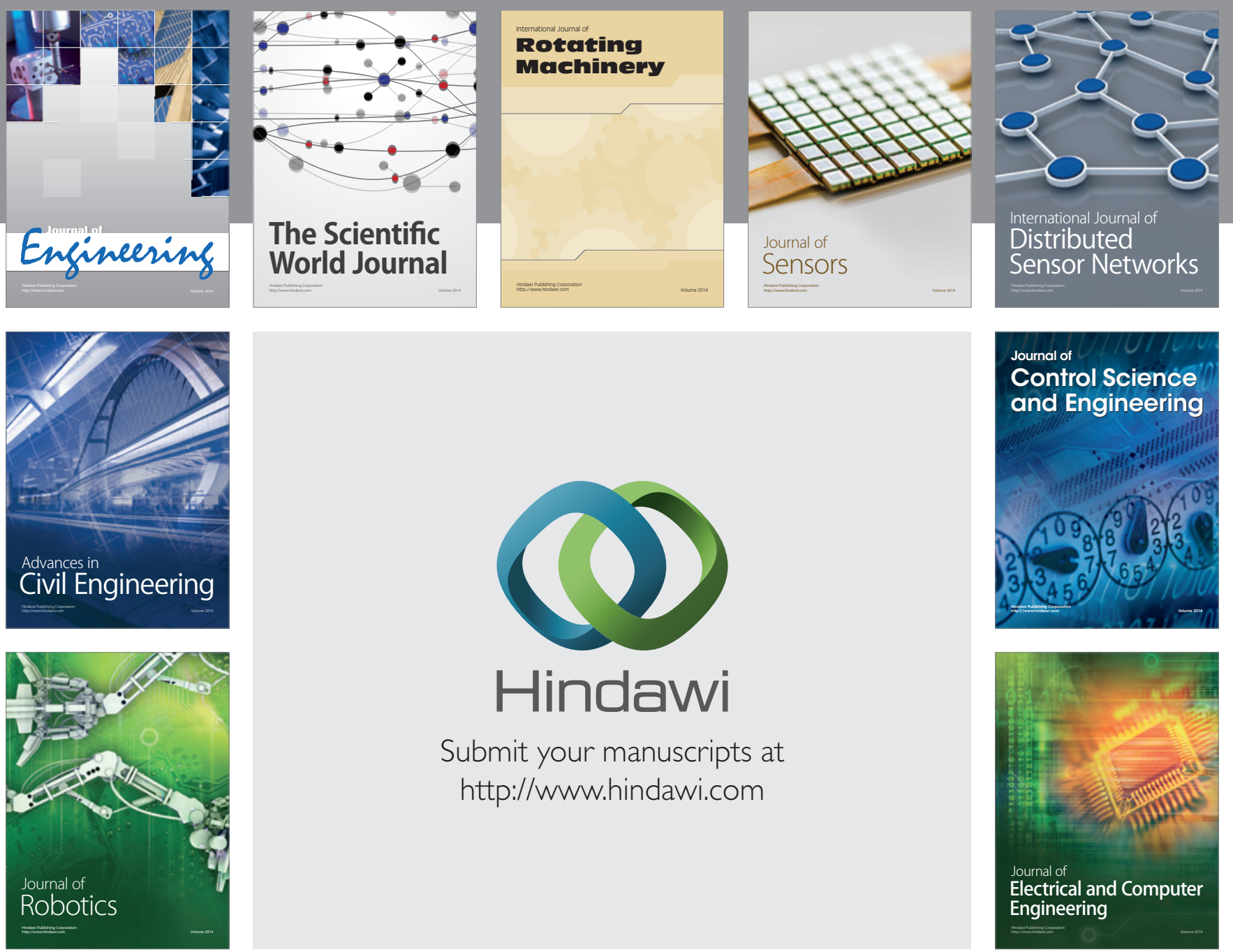

Submit your manuscripts at

http://www.hindawi.com
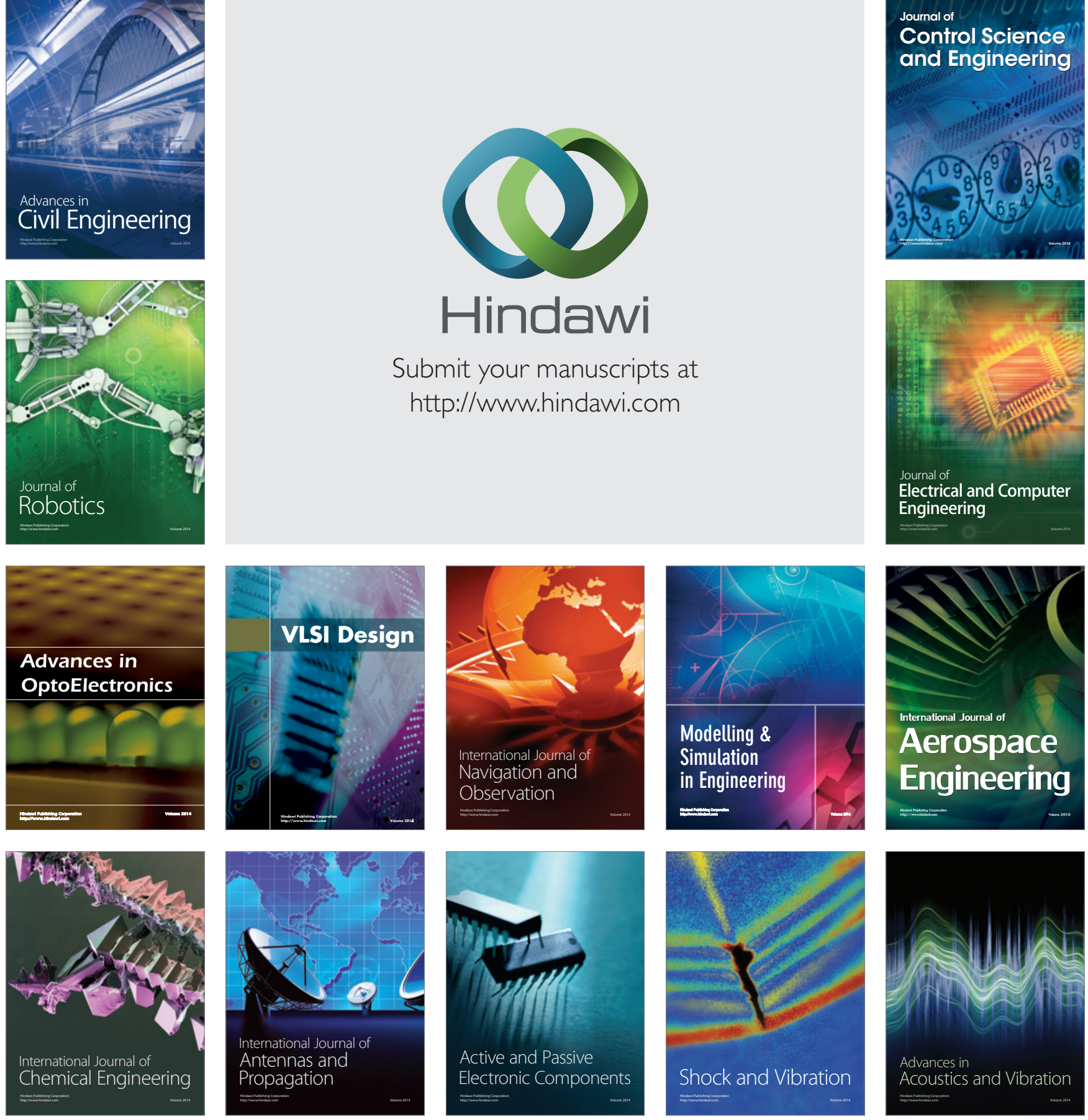